\title{
Impact of diabetes mellitus on acute outcomes of percutaneous coronary intervention in chronic total occlusions: insights from a US multicentre registry
}

\author{
J. R. Martinez-Parachini ${ }^{1}$, A. Karatasakis ${ }^{1}$, D. Karmpaliotis ${ }^{3}$, K. Alaswad ${ }^{2}$, F. A. Jaffer ${ }^{4}$, R. \\ W. Yeh ${ }^{5}$, M. Patel ${ }^{6}$, J. Bahadorani ${ }^{6}$, A. Doing ${ }^{7}$, P.-K. Nguyen-Trong ${ }^{1}$, B. A. Danek ${ }^{1}$, J. \\ Karacsonyi $^{1}$, A. Alame ${ }^{1}$, B. V. Rangan ${ }^{1}$, C. A. Thompson ${ }^{8}$, Subhash Banerjee ${ }^{1}$, and E. S. \\ Brilakis $^{1}$ \\ 1 VA North Texas Healthcare System and UT Southwestern Medical Center, Dallas, TX \\ ${ }^{2}$ Henry Ford Hospital, Detroit, MI \\ ${ }^{3}$ Columbia University, New York, NY \\ ${ }^{4}$ Massachusetts General Hospital and Harvard Medical School, Boston, MA \\ ${ }^{5}$ Beth Israel Deaconess Medical Center and Harvard Medical School, Boston, MA \\ ${ }^{6}$ VA San Diego Healthcare System and University of California San Diego, San Diego, CA \\ ${ }^{7}$ Medical Center of the Rockies, Loveland, CO \\ ${ }^{8}$ Boston Scientific, Natick, MA, USA
}

\begin{abstract}
Aim-To examine the impact of diabetes mellitus on procedural outcomes of patients who underwent percutaneous coronary intervention for chronic total occlusion.

Methods-We assessed the impact of diabetes mellitus on the outcomes of percutaneous coronary intervention for chronic total occlusion among 1308 people who underwent such procedures at 11 US centres between 2012 and 2015.
\end{abstract}

Results-The participants' mean \pm SD age was $66 \pm 10$ years, $84 \%$ of the participants were men and $44.6 \%$ had diabetes. As compared with participants without diabetes, participants with diabetes were more likely to have undergone coronary artery bypass graft surgery (38 vs $31 \%$; $P=0.006$ ), and to have had previous heart failure ( $35 \mathrm{vs} 22 \% ; P=0.0001$ ) and peripheral arterial disease (19 vs $13 \% ; P=0.002)$. They also had a higher BMI $\left(31 \pm 6 \mathrm{~kg} / \mathrm{m}^{2}\right.$ vs $29 \pm 6 \mathrm{~kg} / \mathrm{m}^{2}$; $P=0.001)$, similar Japanese chronic total occlusion scores ( $2.6 \pm 1.2$ vs $2.5 \pm 1.2 ; P=0.82$ ) and similar final successful crossing technique: antegrade wire escalation (46 vs $47 \% ; P=0.66$ ), retrograde (30 vs $28 \% ; P=0.66$ ) and antegrade dissection re-entry ( 24 vs $25 \% ; P=0.66$ ). Technical

Correspondence to: Emmanouil S. Brilakis. esbrilakis@gmail.com.

Supporting information

Additional Supporting Information may be found in the online version of this article: Table S1 Technical success in people with and without diabetes at each participating centre 
(91 vs $90 \% ; P=0.80$ ) and procedural ( 89 vs $89 \% ; P=0.93$ ) success was similar in the two groups, as was the incidence of major adverse cardiac events $(2.2$ vs $2.5 \% ; P=0.61)$.

Conclusions-In a contemporary cohort of people undergoing percutaneous coronary intervention for chronic total occlusion, nearly one in two (45\%) had diabetes mellitus. Procedural success and complication rates were similar in people with and without diabetes.

\section{Introduction}

Diabetes mellitus is highly and increasingly prevalent among people with coronary artery disease, including those undergoing percutaneous coronary intervention (PCI) for chronic total occlusion [1,2]. Diabetes has been associated with multivessel coronary artery disease, arterial calcification, high risk of peripheral artery disease and impaired left ventricular systolic function [3]. There are few studies investigating whether the presence of diabetes mellitus affects the procedural outcomes of chronic total occlusion PCI [3-6]; this was the focus of the present study.

\section{Methods}

\section{Study participants}

We examined the clinical and angiographic records of people who underwent PCI for chronic total occlusion between May 2012 and September 2015 by experienced operators at 11 centres in the USA (Table S1). Only the first procedure was included in the present analysis. Data collection was performed prospectively and retrospectively and recorded in a chronic total occlusion database (Prospective Global Registry for the Study of Chronic Total Occlusion Intervention: PROGRESS CTO, Clinicaltrials.gov Identifier: NCT02061436) [1,7-14]. Some centres only enrolled participants during part of the study period because of the enrolment of the latter in other studies. The study was approved by the institutional review boards of each site. Study data were collected and managed using REDCap electronic data capture tools hosted at University of Texas Southwestern Medical Center [20].

\section{Definitions}

Diabetes mellitus was defined as current intake of hypoglycaemic medications or elevated levels $(>7.0 \mathrm{mmol} / \mathrm{l})$ of fasting blood glucose on two separate occasions $[4,15]$. Coronary chronic total occlusions were defined as coronary lesions with thrombolysis in myocardial infarction grade 0 flow of at least 3-month duration. Estimation of the occlusion duration was based on first onset of anginal symptoms, history of myocardial infarction in the target vessel territory, or comparison with a previous angiogram.

Technical success of PCI for chronic total occlusion was defined as successful chronic total occlusion revascularization with achievement of $<30 \%$ residual diameter stenosis within the treated segment and restoration of thrombolysis in myocardial infarction grade 3 antegrade flow. Procedural success was defined as achievement of technical success with no in-hospital major adverse cardiac events (MACE). In-hospital MACE included any of the following adverse events prior to hospital discharge: death; myocardial infarction; recurrent symptoms 
requiring urgent repeat target vessel revascularization with PCI or coronary artery bypass graft surgery; tamponade requiring either pericardiocentesis or surgery; and stroke.

\section{Statistical analysis}

Continuous data were reported as mean $\pm \mathrm{SD}$ (normally distributed data) or median and interquartile range (non-normally distributed data) and compared using $t$-test or Wilcoxon rank-sum test, as appropriate. Categorical data were presented as frequencies or percentages and compared using chi-squared or Fisher's exact test, as appropriate. A two-sided $P$ value of $<0.05$ was considered statistically significant. All statistical analyses were performed using JMP version 12.0 (SAS Institute, Cary, NC, USA).

\section{Results}

\section{Clinical and angiographic characteristics}

During the study period, 1308 participants underwent 1333 chronic total occlusion PCI procedures at the study sites, but only the first chronic total occlusion intervention was included. The mean \pm SD participant age was $65.5 \pm 10.2$ years, $84.2 \%$ of the participants were men, $41 \%$ had a history of myocardial infarction, $65 \%$ had previously undergone PCI, $34 \%$ had previously undergone coronary artery bypass graft surgery and $45 \%$ had diabetes mellitus (Table 1). As compared with participants without diabetes, participants with diabetes had a higher prevalence of hypertension, dyslipidaemia and previous coronary artery bypass graft, but overall chronic total occlusion lesion complexity was similar in the two groups. The prevalence of moderate/severe calcification ( $61 \mathrm{vs} 56 \% ; P=0.12$ ), and proximal cap ambiguity (33 vs $30 \% ; P=0.27$ ) was similar among participants with and without diabetes.

\section{Procedural outcomes and complications}

Technical (90.7 vs $90.3 \% ; P=0.8$ ) and procedural ( 89.3 vs $89.1 \% ; P=0.9)$ success was similar in participants with and without diabetes mellitus (Table 1). The final successful crossing strategy was also similar between the two groups (retrograde: 30 vs $27.7 \%$; antegrade wire escalation: 45.8 vs $47.2 \%$; antegrade dissection and re-entry: 24 vs $25 \%$; $P=$ 0.66). The duration of the procedure and fluoroscopy time were similar in both groups; however, the radiation dose was higher in participants with diabetes, whereas contrast volume was lower. MACE occurred in 30 of 1308 (2.4\%) participants, with similar frequency in those with and without diabetes mellitus: death $(0.4 \mathrm{vs} 0.3 \% ; P=0.51)$, myocardial infarction ( 1.3 vs $0.5 \% ; P=0.11)$, stroke ( 0.4 vs $0.1 \% ; P=0.4)$, emergency PCI $(0.3$ vs $0.3 \% ; P=0.82)$, emergency coronary artery bypass graft (none) and emergency pericardiocentesis $(0.6$ vs $0.6 \% ; P=0.99)$.

\section{Discussion}

The main findings of the present study were (1) that diabetes was highly prevalent among people undergoing PCI for chronic total occlusion and (2) that similar success and complication rates were found in people with diabetes as compared with people without diabetes. 
Nearly one in two participants who underwent PCI for chronic total occlusion in the present study (44.6\%) had diabetes mellitus, attesting to its important role in the development of coronary atherosclerosis. The high prevalence of diabetes is probably, at least in part, associated with the high prevalence of obesity (the mean BMI was $30.4 \pm 6.2 \mathrm{~kg} / \mathrm{m}^{2}$ ). Similarly, in another large contemporary chronic total occlusion PCI series, the Outcomes, Patient Health Status, and Efficiency In Chronic Total Occlusion Hybrid Procedures (OPEN CTO) registry (presented at the TCT 2015 meeting, San Francisco, CA, USA), the prevalence of diabetes mellitus was $41.4 \%$ and the mean BMI was $30.8 \pm 9.1 \mathrm{~kg} / \mathrm{m}^{2}$. The prevalence of diabetes was $39.5 \%$ among 281 people who underwent retrograde PCI for chronic total occlusion in Japan [16], 43.3\% among 498 people who were enrolled in the Japan chronic total occlusion registry [17], and 29\% among 1395 people in the European Registry of chronic total occlusions (ERCTO) [18].

In contrast to some previous studies, the present study did not find any significant difference in procedural techniques and outcomes of PCI for chronic total occlusion between people with and without diabetes mellitus. The results showed high technical and procedural success and low MACE rates, probably related to inclusion of high-volume centres and experienced operators. Sohrabi et al. [5] reported a higher incidence of in-hospital adverse events among people with diabetes, with higher rates of repeat revascularization (20.6 vs $7 \% ; P=0.04)$, bleeding ( 2.9 vs $0.8 \%)$, cardiac death ( 2.9 vs $0 \%)$ and myocardial infarction ( 2.9 vs $0.8 \%$ ); however, long-term outcomes were not affected. Galassi et al. [18] showed a $27.5 \%$ prevalence of diabetes in successful PCI procedures for chronic total occlusion and $33.7 \%$ in unsuccessful procedures $(P=0.04)$. Similarly to the present study, Ruiz-Garcia et al. [3] reported similar favourable clinical and angiographic outcomes in people with and without diabetes. Achievement of similar success rates in spite of slightly worse angiographic characteristics among people with diabetes (Table 1) could, at least in part, be explained by application of the hybrid approach to chronic total occlusion crossing that advocates systematic assessment of the angiogram and early change if the initially selected strategy is unsuccessful [19].

The present study has limitations; it was observational and only reported procedural outcomes without long-term follow-up, which might be worse among people with diabetes because of higher risk of in-stent restenosis [5]. There was no clinical event adjudication by a clinical events committee. Multiple comparisons were performed on the characteristics of the two study groups increasing the likelihood of finding a spurious association. All procedures were performed at centres experienced in chronic total occlusion contemporary crossing techniques and strategies [19]. The results of the present study may therefore not be generalizable to settings with limited experience in PCI for chronic total occlusion.

In summary, PCI was performed for chronic total occlusion in people with and without diabetes mellitus with equally high success and equally low complication rates.

\section{Supplementary Material}

Refer to Web version on PubMed Central for supplementary material. 


\section{Acknowledgments}

Funding sources

The REDCap tools used for the study were supported by CTSA National Institutes of Health (NIH) Grant UL1RR024982.

Competing interests

D.K. has served on speaker bureaus for Abbott Vascular, Medtronic and Boston Scientific. K.A. has received consulting fees from Terumo and Boston Scientific and has served as a consultant for Abbott Laboratories. F.A.J. has served as a consultant to Boston Scientific, Siemensand Merck, and received non-financial research support from Abbott Vascular, and a research grant from National Institutes of Health (HL-R01-108229). R.W.Y. has received a Career Development Award (1K23HL118138) from the National Heart, Lung, and Blood Institute. B.V.R. has received research grants from InfraReDx and the Spectranetics Corporation. C.A.T. is an employee of Boston Scientific. Dr. Banerjee has received research grants from Gilead and the Medicines Company, has served as a consultant/speaker and received honoraria from Covidien and Medtronic, and has ownership in MDCARE Global (spouse) and intellectual property in HygeiaTel. E.S.B. has received consulting/speaker honoraria from Abbott Vascular, Asahi, Boston Scientific, Elsevier, Somahlution, St Jude Medical and Terumo, has received research support from Boston Scientific and InfraRedx and is married to an employee of Medtronic.

\section{References}

1. Christopoulos G, Karmpaliotis D, Alaswad K, Yeh RW, Jaffer FA, Wyman RM, et al. Application and outcomes of a hybrid approach to chronic total occlusion percutaneous coronary intervention in a contemporary multicenter US registry. Int J Cardiol. 2015; 198:222-228. [PubMed: 26189193]

2. Michael TT, Mogabgab O, Fuh E, Patel VG, El Sabbagh A, Alomar ME, et al. Application of the "hybrid approach" to chronic total occlusion interventions: a detailed procedural analysis. J Interv Cardiol. 2014; 27:36-43. [PubMed: 24456334]

3. Ruiz-Garcia J, Teles R, Rumoroso JR, Cyrne Carvalho H, Goicolea FJ, Moreu J, et al. Comparison between diabetic and non-diabetic patients after successful percutaneous coronary intervention for chronic total occlusions in the drug-eluting stent era. Rev Port Cardiol. 2015; 34:263-70. [PubMed: 25840644]

4. Rha SW, Choi CU, Na JO, Lim HE, Kim JW, Kim EJ, et al. Comparison of 12-month clinical outcomes in diabetic and nondiabetic patients with chronic total occlusion lesions: a multicenter study. Coron Artery Dis. 2015; 26:699-705. [PubMed: 26407238]

5. Sohrabi B, Ghaffari S, Habibzadeh A, Chaichi P. Outcome of diabetic and non-diabetic patients undergoing successful percutaneous coronary intervention of chronic total occlusion. J Cardiovasc Thorac Res. 2011; 3:45-48. [PubMed: 24250951]

6. De Felice F, Fiorilli R, Parma A, Nazzaro MS, Dibra A, Musto C, et al. Clinical outcome of patients with diabetes mellitus and chronic total occlusion treated with drug-eluting stents. J Invasive Cardiol. 2008; 20:651-654. [PubMed: 19057029]

7. Alaswad K, Menon RV, Christopoulos G, Lombardi WL, Karmpaliotis D, Grantham JA, et al. Transradial approach for coronary chronic total occlusion interventions: Insights from a contemporary multicenter registry. Catheter Cardiovasc Interv. 2015; 85:1123-1129. [PubMed: 25640902]

8. Christopoulos G, Kandzari DE, Yeh RW, Jaffer FA, Karmpaliotis D, Wyman MR, et al. Development and Validation of a Novel Scoring System for Predicting Technical Success of Chronic Total Occlusion Percutaneous Coronary Interventions: The PROGRESS CTO (Prospective Global Registry for the Study of Chronic Total Occlusion Intervention) Score. JACC Cardiovasc Interv. 2016; 9:1-9. [PubMed: 26762904]

9. Christopoulos G, Karmpaliotis D, Alaswad K, Lombardi WL, Grantham JA, Rangan BV, et al. The efficacy of "hybrid" percutaneous coronary intervention in chronic total occlusions caused by instent restenosis: Insights from a US multicenter registry. Catheter Cardiovasc Interv. 2014; 84:646651. [PubMed: 24585508]

10. Christopoulos G, Karmpaliotis D, Wyman MR, Alaswad K, McCabe J, Lombardi WL, et al. Percutaneous Intervention of Circumflex Chronic Total Occlusions Is Associated With Worse 
Procedural Outcomes: Insights From a Multicentre US Registry. Can J Cardiol. 2014; 30:15881594. [PubMed: 25442459]

11. Christopoulos G, Menon RV, Karmpaliotis D, Alaswad K, Lombardi W, Grantham A, et al. The Efficacy and Safety of the "Hybrid" Approach to Coronary Chronic Total Occlusions: Insights From a Contemporary Multicenter US Registry and Comparison With Prior Studies. J Invasive Cardiol. 2014; 26:427-432. [PubMed: 25198485]

12. Christopoulos G, Menon RV, Karmpaliotis D, Alaswad K, Lombardi W, Grantham JA, et al. Application of the "hybrid approach" to chronic total occlusions in patients with previous coronary artery bypass graft surgery (from a Contemporary Multicenter US registry). Am J Cardiol. 2014; 113:1990-1994. [PubMed: 24793678]

13. Christopoulos G, Wyman RM, Alaswad K, Karmpaliotis D, Lombardi W, Grantham JA, et al. Clinical Utility of the Japan-Chronic Total Occlusion Score in Coronary Chronic Total Occlusion Interventions: Results from a Multicenter Registry. Circ Cardiovasc Interv. 2015; 8:e002171. [PubMed: 26162857]

14. Sapontis J, Christopoulos G, Grantham JA, Wyman RM, Alaswad K, Karmpaliotis D, et al. Procedural failure of chronic total occlusion percutaneous coronary intervention: Insights from a multicenter US registry. Catheter Cardiovasc Interv. 2015; 85:1115-1122. [PubMed: 25557905]

15. Standards of medical care in diabetes-2015: summary of revisions. Diabetes Care. 2015; 38(Suppl):S4.

16. Muramatsu T, Tsukahara R, Ito Y, Ishimori H, Park SJ, de Winter R, et al. Changing strategies of the retrograde approach for chronic total occlusion during the past 7 years. Catheter Cardiovasc Interv. 2013; 81:E178-185. [PubMed: 22517670]

17. Morino Y, Kimura T, Hayashi Y, Muramatsu T, Ochiai M, Noguchi Y, et al. In-hospital outcomes of contemporary percutaneous coronary intervention in patients with chronic total occlusion insights from the J-CTO Registry (Multicenter CTO Registry in Japan). JACC Cardiovasc Interv. 2010; 3:143-151. [PubMed: 20170870]

18. Galassi AR, Tomasello SD, Reifart N, Werner GS, Sianos G, Bonnier H, et al. In-hospital outcomes of percutaneous coronary intervention in patients with chronic total occlusion: insights from the ERCTO (European Registry of Chronic Total Occlusion) registry. EuroIntervention. 2011; 7:472-479. [PubMed: 21764666]

19. Brilakis ES, Grantham JA, Rinfret S, Wyman RM, Burke MN, Karmpaliotis D, et al. A percutaneous treatment algorithm for crossing coronary chronic total occlusions. JACC Cardiovasc Interv. 2012; 5:367-379. [PubMed: 22516392]

20. Paul A, Harris PA, Taylor R, Thielke R, Payne J, Gonzalez N, Conde JG. Research electronic data capture (REDCap) - A metadata-driven methodology and workflow process for providing translational research informatics support. J Biomed Inform. 2009; 42:377-381. Supported by CTSA NIH Grant UL1-RR024982. [PubMed: 18929686] 


\section{What's new?}

- Chronic total occlusions are a common and complex type of coronary artery disease that can be challenging to treat with percutaneous coronary intervention (PCI). We examined a large, multicentre registry of PCI for chronic total occlusion to determine the impact of diabetes mellitus on outcomes. Diabetes was highly prevalent (44.6\%).

- $\quad$ Although diabetes was associated with more complex clinical and angiographic characteristics, it did not influence procedural success and complications, suggesting that the presence of diabetes is not a contraindication to PCI for chronic total occlusion. 


\section{Table 1}

Clinical and angiographic characteristics and outcomes of the study participants and lesions, classified according to diabetic status

\begin{tabular}{|c|c|c|c|c|}
\hline Clinical characteristic & $\begin{array}{l}\text { Overall } \\
n=1308\end{array}$ & $\begin{array}{c}\text { No diabetes } \\
\qquad n=724\end{array}$ & $\begin{array}{c}\text { Diabetes } \\
n=584\end{array}$ & $P$ \\
\hline Mean \pm age ${ }^{*}$, years & $65.5 \pm 10.2$ & $65.7 \pm 10.6$ & $65.3 \pm 9.6$ & 0.26 \\
\hline Male, $\%$ & 84.2 & 85.5 & 82.5 & 0.13 \\
\hline $\mathrm{BMI}^{*}, \mathrm{~kg} / \mathrm{m}^{2}$ & $30.4 \pm 6.2$ & $29.2 \pm 5.7$ & $31.3 \pm 6.4$ & 0.001 \\
\hline Dyslipidaemia, \% & 94.4 & 92.8 & 96.4 & 0.0049 \\
\hline Current smoking, $\%$ & 28.1 & 29.6 & 26.3 & 0.29 \\
\hline Heart failure, $\%$ & 27.6 & 21.7 & 31.9 & 0.0001 \\
\hline Histoiy of MI, \% & 42.1 & 42.2 & 41.9 & 0.92 \\
\hline Histoiy of CABG, $\%$ & 34.1 & 31.0 & 38.1 & 0.0067 \\
\hline Baseline creatinine ${ }^{*}, \mu \mathrm{mol} / 1$ & $88(76-109)$ & $88(74-105)$ & $97(79-120)$ & $<0.0001$ \\
\hline Previous PCI, \% & 64.8 & 64.4 & 65.4 & 0.69 \\
\hline Previous chronic total occlusion PCI failure, $\%$ & 17.7 & 19.0 & 15.9 & 0.15 \\
\hline Peripheral arterial disease, $\%$ & 15.6 & 12.8 & 18.9 & 0.0027 \\
\hline Technical success, $\%$ & 90.5 & 90.3 & 90.7 & 0.8 \\
\hline Procedural success, $\%$ & 89.3 & 89.1 & 89.3 & 0.93 \\
\hline MACE, \% & 2.4 & 2.5 & 2.2 & 0.61 \\
\hline Angiographic characteristic & 1308 lesions & 724 lesions & 584 lesions & \\
\hline Chronic total occlusion target vessel, $\%$ & 56.9 & 58.1 & 55.6 & \\
\hline Right coronary artery & 19.7 & 18.3 & 21.6 & 0.34 \\
\hline Left circumflex artery & 23.3 & 23.6 & 22.8 & \\
\hline \multicolumn{5}{|l|}{ Left anterior descending artery } \\
\hline Japan chronic total occlusion score ${ }^{*}$ & $2.5 \pm 1.2$ & $2.5 \pm 1.2$ & $2.6 \pm 1.2$ & 0.82 \\
\hline
\end{tabular}

CABG, coronary artery bypass graft surgery; MI, myocardial infarction; PCI, percutaneous coronary intervention; MACE major adverse cardiovascular events.

Mean \pm SD or median (interquartile range). 